\title{
Workload of a new district AIDS counselling unit, April 1987 to March 1988
}

\author{
R BOR,${ }^{*} \dagger$ J ELFORD, $\ddagger$ R MILLER, ${ }^{*}$ L PERRY,$*$ HSALT ${ }^{*} \dagger$ \\ From the *District AIDS Counselling Unit, Royal Free Hospital, and the Departments of $\dagger$ Clinical Psychology \\ and $\ddagger$ Clinical Epidemiology and General Practice, Royal Free Hospital School of Medicine, London
}

SUMMARY The Hampstead district AIDS counselling unit in London was opened in January 1987. It is staffed by a clinical psychologist, a social worker, and an administrator. From April 1987 to March 1988, 141 new patients and their relatives were referred from a range of clinical departments and 544 counselling sessions were provided. In addition, 666 staff consultations were organised to help colleagues manage some of the psychosocial problems of patients. An increase in demand during 1988-89 and a need for additional resources are anticipated.

A strong case is seen for training other members of health care teams so that they may counsel patients with AIDS without referring them to the unit.

The role of counselling in managing patients with AIDS or infected with human immunodeficiency virus (HIV) has already been described. ${ }^{123}$ Although there have been rapid advances in the biomedical field in relation to AIDS and HIV, relatively little is known about the impact of AIDS on the health services. This report describes the workload of the Hampstead district AIDS counselling unit at the Royal Free Hospital from April 1987 to March 1988. (The unit opened in January 1987.) Such information is essential if services are to be planned according to need. Furthermore, patterns of referrals to AIDS counsellors must be studied so that training in AIDS counselling skills can be offered in specialities with a large number of patients. It should be noted that AIDS counselling has been available in the hospitals of this district since the disease was first reported in the United Kingdom. Although the data reported here reflect the current activities of AIDS counsellors, they refer to a new and evolving service. The workload is likely to change in the future as demand on the service increases, patterns of disease expression change, new experimental drugs are introduced, and other professionals develop their own counselling skills.

\section{The task of AIDS counsellors}

AIDS counsellors in a clinical setting are drawn from

Address for reprints: Dr Robert Bor, District AIDS Counselling Unit, Royal Free Hospital, Pond Street, London NW3 2QG

Accepted for publication 14 December 1988 many professional backgrounds, including medicine, nursing, social work, and psychology. AIDS counsellors help patients to live with a potentially life threatening condition and to manage the stress that may accompany this. They also help patients with AIDS and HIV infection to make decisions about how they want to live and, in some cases, die. An important part of the AIDS counsellor's task is to help patients resolve relationship difficulties that arise from their positive HIV antibody test results or diagnoses of AIDS.

The work of an AIDS counsellor is also, to some extent, preventative. Counsellors advise patients how to reduce the risk of HIV transmission. They may also prevent the stress that accompanies any life threatening illness from leading to psychiatric problems in patients and members of their families. ${ }^{4}$ The "worried well", who despite negative rest results and reassurance continue to believe themselves to be infected, may also require extensive counselling. Furthermore, some AIDS counsellors advise colleagues who seek guidance about how to manage some of the psychosocial consequences of an AIDS diagnosis with patients and their relatives.

Table 1 lists 10 groups of patients, relatives, or staff identified as being likely to be referred to a clinically based AIDS counsellor.

\section{The hospital setting}

The district AIDS counselling unit was established in January 1987 to provide a comprehensive clinical counselling service for patients to be seen in any unit, 
Table 1 Groups of people referred to AIDS counsellors in a clinical setting

1 Patients who have concerns or queries about AIDS, regardless of their clinical status.

2 Patients who are referred for the human immunodeficiency (HIV) antibody test.

3 Patients who are HIV antibody negative but who continue to present with AIDS related worries.

4 Patients who are HIV antibody positive and symptomless.

5 Patients who are HIV antibody positive and who are becoming unwell.

6 Patients who have developed AIDS.

7 Patients who are being offered, or who are being considered for, antiviral treatments.

8 The sexual contacts, loved ones, or family of any of the above, if the patient has given his or her permission.

9 The close contacts of a deceased patient who require bereavement counselling.

10 Staff with concerns about AIDS or occupationally exposed to HIV (in conjunction with the occupational health department).

department, medical specialty, or hospital in the Hampstead health district. The unit is currently staffed by a social worker (AIDS counselling co-ordinator), a clinical psychologist (district AIDS counsellor), and a unit administrator. Separate AIDS counselling services are also offered in the supraregional haemophilia centre and the sexually transmitted disease (STD) clinic, both of which are based in the main hospital building. Patients from the STD clinic are not routinely seen by members of the AIDS counselling unit unless a special referral is made, which is most often when patients are becoming unwell. Only these special referrals from the STD clinic and the haemophilia centre are included in data presented here. Patients in the haemophilia centre are seen by a specialist counsellor (who also happens to be the AIDS counselling co-ordinator), and she keeps a separate record of all referrals. These are not presented here.

The statistics recorded in this paper refer to the year from April 1987 to March 1988 inclusive. Patients were seen on wards, in outpatient departments, and occasionally at home. Referrals were always taken up within 24 hours. Emergency referrals were made from time to time to the AIDS counsellor on call who carries an "aircall" outside normal working hours. Patients may be seen on their own or with their sexual partner or family. Support groups for patients with AIDS or HIV are facilitated by the AIDS counsellor.

\section{Statistics for April 1987 to March 1988}

\section{CLINICAL CASELOAD}

Table 2 shows that 117 new patients were referred for AIDS counselling during the year: 105 were seen as outpatients and 12 as inpatients. In addition, 24 relatives were referred to the unit. The fact that most patients referred were outpatients probably reflects the pattern of presentation to the hospital of people with
Table 2 People seen in AIDS counselling unit, April 1987 to March 1988

\begin{tabular}{lcll}
\hline & $\begin{array}{l}\text { New } \\
\text { patients }\end{array}$ & $\begin{array}{l}\text { Follow up } \\
\text { appointments }\end{array}$ & $\begin{array}{l}\text { Total } \\
\text { counselling } \\
\text { sessions }\end{array}$ \\
\hline Inpatients & 12 & & \\
Outpatients & 105 & & \\
Relatives & 24 & 403 & 544 \\
Total & 141 & 4 & \\
\hline
\end{tabular}

*Follow up appointments were not analysed by patient status.

AIDS or HIV related concerns. Patients and relatives kept 403 follow up appointments. We recorded 544 contacts with patients or relatives during the year. On average, each person referred was seen on four occasions. Our experience suggests that people who have been inpatients require following up more often than outpatients. Each counselling session lasted, on average, 50 minutes. These figures do not include the 341 telephone enquiries received during the year.

The number of patients referred to the unit increased steadily from April to November 1987, after which it levelled off at an average of 15.5 new referrals each month (fig 1). Assuming that the more recent pattern of referrals (since November 1987) continues, we predict that about 190 new patients and their relatives will be referred to the AIDS counselling unit in 1988. As a consequence, total patient contacts will probably increase from 544 in $1987-8$ to over 700 in 1988-9.

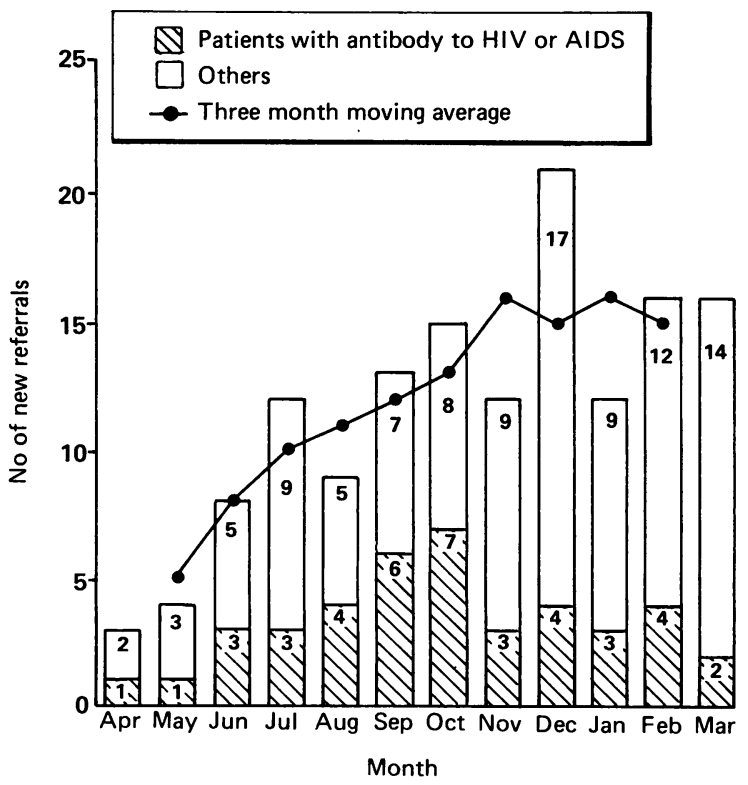

Fig 1 Monthly numbers of new referrals to AIDS counselling unit, April 1987 to March 1988. 
It is important to note that these data on new referrals cannot be used to estimate the incidence of AIDS or infection with HIV in the Hampstead health district for several reasons. Some of those referred may live outside the district, while others, who live in the district, may attend another London hospital. Not all patients are referred for counselling, and several months elapsed before regular referrals were established after the AIDS counselling unit opened in January 1987. Furthermore, because of growing public awareness, many people referred for counselling before being tested were subsequently found to be HIV antibody negative.

\section{CONSULTATIONS WITH THE REFERRING TEAM}

An important part of the workload of the AIDS counselling unit is to advise other staff about the psychosocial management of patients. Providing such advice enables these members of staff to take on some of the skills of the AIDS counsellor. It can also contribute to co-ordinated patient management. This may result in fewer psychological problems with patients and improved patient management. Although the number of requests for advice is expected to rise in the immediate future, the counsellors anticipate that such requests will decrease in the long term as other members of staff become more skilled and confident in dealing with these patients themselves. During the year members of staff were seen on 666 occasions, some having been seen more than once (fig 2). A staff

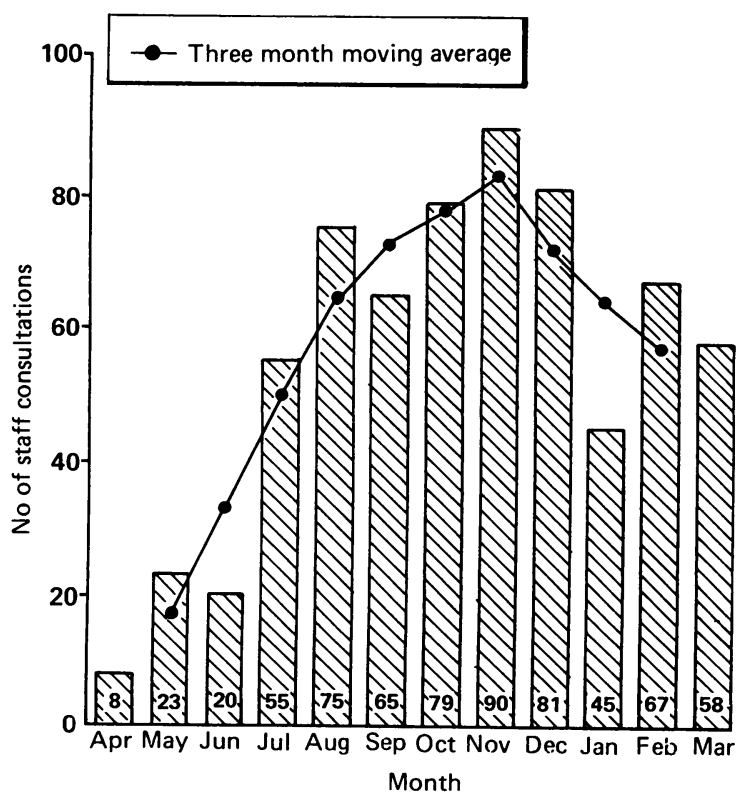

Fig 2 Monthly numbers of staff consultations with AIDS counselling unit, April 1987 to March 1988.
Table 3 Source of referrals to AIDS counselling unit, April 1987 to March 1988

\begin{tabular}{lc}
\hline Speciality or department & $\begin{array}{c}\text { No of } \\
\text { referrals }\end{array}$ \\
\hline Sexually transmitted diseases & 30 \\
Self referrals & 30 \\
Relatives of patients & 24 \\
General medicine & 11 \\
Cardiology & 6 \\
Obstetrics and gynaecology & 5 \\
Psychiatry & 5 \\
Haemophilia and haematology & 4 \\
Infectious diseases & 4 \\
Accident and emergency & 3 \\
Ear, nose, and throat & 3 \\
Oral and dental surgery & 3 \\
Surgery & 1 \\
Intensive therapy unit & 1 \\
Occupational health & 1 \\
Radiotherapy and oncology & 1 \\
Neurosurgery & 1 \\
Endocrinology & 5 \\
Other (such as general practitioner) & 141 \\
Total & \\
\hline
\end{tabular}

Table 4 Some main concerns of patients with AIDS or HIV infection

Fear of social isolation and stigma.

Disclosure of sexuality or past sexual relationships.

Loss of friends, lovers, or family.

Loss of a sense of the future.

Living with uncertainty.

Fear of disfigurement and pain during illness.

Stress associated with keeping secrets.

Fear of neurological impairment and loss of ability to make decisions.

Making decisions about having children, in some cases.

Making decisions about life sustaining measures, such as

resuscitation and ventilation.

Dilemmas about entering drug trials and consenting to treatment that may not offer cure.

consultation was offered at least once for every new patient at the time of referral. Staff consultations were rarely longer than 15 minutes.

SOURCE OF REFERRALS

Table 3 shows that patients were referred for AIDS counselling from several departments and clinical specialities. Most $(67 \%, 95 / 141)$ of those seen were self referrals, were referred from general medicine or the Marlborough department of sexually transmitted diseases, or were relatives of patients.

THE MAIN CONCERNS OF PATIENTS WITH AIDS OR HIV INFECTION

Our experience has shown that patients have specific anxieties that AIDS counsellors need to address. These are listed in table 4.

ALLOCATION OF TIME IN THE UNIT

About $80 \%$ of the district AIDS counsellor's time 
during the year was devoted to clinical contacts, which included patient and family counselling sessions as well as staff liaison and consultation. A further $15 \%$ of his time was allocated to teaching and research, and the balance of $5 \%$ was spent on administration.

\section{Discussion}

The numbers given in this paper indicate a progressive increase in new referrals made to the Hampstead district AIDS counselling unit from April to November 1987, after which they levelled off at an average of 15.5 a month. We offer several reasons for this trend. Firstly, public awareness about AIDS increased after the media campaigns in November 1986 and February $1987 .{ }^{56}$ Many more people came to clinics requesting the test for antibodies to HIV or with AIDS related concerns. Secondly, the relationship problems that many patients with AIDS or HIV infection face are complex and increasingly require specialist interventions. Lastly, because the incidence of HIV infection is still increasing, referrals for AIDS counselling and requests for staff consultations are expected to rise, at least in the immediate future. As the AIDS counselling unit is a new service in the district, however, the future workload cannot be predicted with any degree of accuracy.

The counselling technique used in the unit has been described elsewhere. ${ }^{4}$ Briefly, we encourage patients to develop appropriate skills that will reduce their reliance on counsellors. The initial task of the AIDS counsellor is to establish the nature of each patient's problem and devise the appropriate intervention. Not all patients, however, will need professional counselling.
As health care staff encounter more patients with AIDS, HIV infection, and AIDS associated worries, they will have to develop appropriate skills for working with these people. AIDS counsellors often have the task of helping patients manage their concerns and difficulties. In addition, they may have to counsel patient's relatives and friends. They also have an important role in teaching and enhancing counselling skills in their colleagues. Given the complexity of the problems faced by the growing number of people offering AIDS counselling, there is an obvious need to ensure consistency in their approaches.

We thank Dr D MacDonald Burns of the Marlborough department of sexually transmitted diseases of the Royal Free Hospital for his helpful comments and suggestions, which have been incorporated into this paper. We also thank the special Trustees of the Royal Free Hospital for their encouragement and support.

\section{References}

1 Sherer R. Physician use of the HIV antibody test. JAMA 1988;259:264-5.

2 Miller D, Green J, McCreaner A. Organising a counselling service for problems related to AIDS. Genitourin Med 1986;62: 116-22.

3 Wolcott D, Fawzy F, Pasnau R. AIDS and consultation-liaison psychiatry. Gen Hosp Psych 1985;7:280-92.

4 Miller R, Bor R. AIDS: A guide to clinical counselling. London: Science Press, 1988.

5 Campbell M, Waters W. Public knowledge about AIDS increasing. Br Med J 1987;294:892-3.

6 Mills S, Campbell MJ, Waters WE. Public knowledge of AIDS and the DHSS advertisement campaign. $\mathrm{Br}$ Med $\mathrm{J}$ 1986;293:1089-90.

7 Bor R, Miller R, Perry L. Systemic counselling for patients with AIDS/HIV infections. Family Systems Medicine 1988;6:21-39. 